\title{
Erratum zu: Gesundheitswissenschaften
}

\author{
Robin Haring (Hrsg.)
}

\section{Erratum zu:}

R. Haring et al. (Hrsg.), Gesundheitswissenschaften, Springer Reference Pflege - Therapie Gesundheit, https://doi.org/10.1007/978-3-662-58314-2

Die Originalversion des Impressums wurde korrigiert. Die ISSN wurde korrigiert zu 2662-6942 und 2662-6950 (electronic). 